\title{
Application of Axiomatic Design for the Design of a Safe Collaborative Human-Robot Assembly Workplace
}

\author{
Luca Gualtieri", Erwin Rauch, Rafael Rojas, Renato Vidoni and Dominik T. Matt \\ Faculty of Science and Technology, Free University of Bozen-Bolzano, Bolzano, 39100 Italy
}

\begin{abstract}
In the context of the Industry 4.0 wave, which is currently making its way into production engineering research, human robot collaboration is also a very important topic. With new technologies and ever more intelligent control systems for machines and robots, the cooperation between human and machine has become easier. In the smart factory of the future, robots are working hand in hand with people and support them, when their assistance is needed. However, the implementation of such collaborative humanrobot workplaces is not so easy in practice. The design of collaborative workplaces also presents completely new challenges in terms of safety of the worker. Such a complex problem requires a systematic and structured approach for concept design, in order to avoid loops in the design stage or even worse during implementation. The research team therefore uses a laboratory case study to show how Axiomatic Design can be used as a method to design collaborative human-robot workstations. First, functional requirements for such workplaces are defined. Based on the functional requirements, the design parameters are derived by using the Axiomatic Design mapping and decomposition process. The result is a concept study for a collaborative workplace in the laboratory environment based on Axiomatic Design.
\end{abstract}

\section{Introduction}

With the introduction of Industry 4.0 into production, the cooperation between man and machine is becoming increasingly important. Especially in the field of humanrobot collaboration, an increase in flexibility and an option for automation even with smaller batch sizes is expected. Despite new developments in collaborative robotics, the safety of robot cells plays a major role in the design of production systems.

Commercial collaborative robots are safe as such, but as soon as they are used in a specific application situation, this often changes. For example, the robot can enter or stop in a safety mode when in contact with the operator. However, if the robot is equipped with a dangerous gripper (sharp, pointed), the potential danger can change or increase. This means that the use of collaborative robotics no longer makes sense or that the robots can in turn be used with a safe enclosure. Therefore, possible sources of danger must be identified and eliminated or minimized by appropriate design solutions. A number of norms and standards have been developed for this purpose.

The various standards regulate different cases and situations and are often difficult for the user to understand due to their complexity and scope. In particular, there is a lack of an overview of which standards can be applied and for which situations. Users therefore often have difficulties in applying these standards.
This work uses Axiomatic Design to examine how functional requirements can describe sources of danger and classify them according to the applicable standards. This provides practitioners with a tool for making collaborative workplaces safer in the future. The work is based on a case study in the laboratory and will be extended to practice in a next step with the help of industrial case studies.

\section{Theoretical background - Safety in Human-Robot Collaboration}

Up to now, in order to improve production efficiency, the role of traditional industrial robots was to substitute human operators in repetitive, heavy and unsafe processes [1]. Due to safety requirements, high performance automated machines entail a total insulation by avoiding every kind of contact between humans and the operating parts of the robot. The main solutions are physical and/or optical barriers.

Collaborative industrial robotics introduces new forms of free physical interaction between operators and robots, creating a new paradigm from a human-machine interaction point of view. These machines are re-defining the concept of workplace design, by introducing hybrid and shared workspaces. According to ISO TS 15066 [2], it is possible to define a collaborative workspace as a "space within the operating space where the robot system (including the workpiece) and a human can perform tasks concurrently during production operation".

Corresponding author: 1gualtieri@natec.unibz.it 
This means a common production environment where operators and robots can work hand-by-hand in a safe and efficient way. According to this definition, conventional protective systems designed for traditional industrial robotics no longer apply [3]. For this reason, it is necessary to develop new methods to design and manage the human robot (HR) collaboration and the sharing of workspace, by considering the human operator the main element of the production system [4].

Of course, this is a particular application of the so called anthropocentric or 'human centered design' approach applied to modern industrial human-machine interaction [5]. In addition, new Occupational Health and Safety (OHS) considerations should be properly introduced to ensure a safe collaborative workplace implementation [6]. The actual industrial problem is to define new approaches for the hybrid workspace design, considering OHS issues but also production efficiency requirements. In practice, the main challenge is to ensure operators safety when they are collaborating hand-byhand with high performance robots, in a reconfigurable and therefore dynamic workspace.

In general, a HR collaborative workstation could be defined as a particular kind of robotic cell where the robot has to adapt its behavior according to the presence of the operator, in order to guarantee the safety requirements. Of course, from a production efficiency point of view, it is useful to define some spaces and tasks where the robot can operate in a more performing way, that means in a not-collaborative modality (such as a traditional industrial robot). For this reason, it is necessary to design the workstation safety systems by considering the OHS requirements for collaborative and non-collaborative applications and relative workspaces.

\section{Current design of the manual assembly workplace in the laboratory}

Prior to the Axiomatic design study, the current assembly situation in the laboratory and the product to be assembled are presented.

\subsection{Manual pneumatic cylinder assembly workplace}

This work refers to the study of a safe collaborative workstation using an Axiomatic Design methodology, according to main OHS standards.

In order to perform this work, an existing manual assembly workstation is used as a starting point for the concept development of the collaborative one, even if the proposed design approach could be implemented booth for new as for existing situations (re-design). The abovementioned assembly workstation is a flexible working area for the study of manual assembly of light industrial products (see Fig. 1), located in the Smart Mini Factory laboratory (SMF lab) of the Free University of Bolzano. In particular, it is a manual assembly training workstation where a single operator can completely assemble a pneumatic cylinder. The aim of this workplace is to simulate different assembly conditions and applications in order to analyze the production system performances through task and workplace organization and ergonomics [7].

The workstation is equipped with a mobile workbench, a block-and-tackle for lightweight applications, an integrated Kanban rack, a working procedures panel, a double lighting system, an industrial screwer and a knee lever press.

Main laboratory application are the development of case studies for manual lean assembly, workplace organization, human-centered design and ergonomics. Other analysis refer to safe HR collaboration in hybrid assembly of light products.

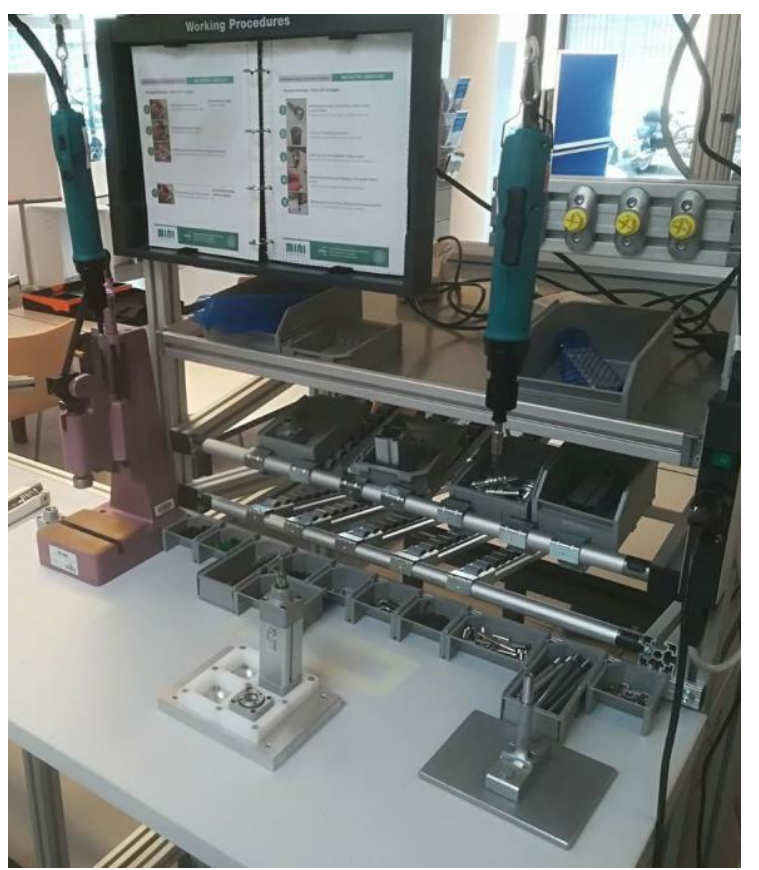

Fig. 1. Manual assembly workstation in the Smart Mini Factory lab.

\subsection{Research objectives}

The aim of this work is to provide useful guidelines for the design of an industrial HR collaborative workstation using an Axiomatic Design approach, mainly focusing on safety perspective.

Since hybrid workstations are a novel topic in modern manufacturing systems, it is necessary to provide new methodologies to design safe shared workspaces and physical HR interactions, also considering the indications provided by major safety of machinery standards.

\section{Design of a Collaborative Human- Robot Assembly Workplace}

This section begins with a brief overview of Axiomatic Design as research and design methodology, followed by the Axiomatic Design approach for designing a safe and collaborative assembly station in our Smart Mini Factory laboratory. 


\subsection{Brief overview of Axiomatic Design}

Axiomatic Design (AD) was developed by Nam P. Suh in the mid-1970s in the pursuit of developing a scientific, generalized, codified, and systematic procedure for design. The methodology gains its name from two axioms in $\mathrm{AD}$ that have to be respected. The first is the Independence Axiom: Maintain the independence of the functional elements, i.e., avoid coupling in the system (e.g., avoiding dependencies between the Design Parameters (DPs) and other Functional Requirements (FRs)). The second is the Information Axiom: Minimize the information content by selecting the solution with the least information content, i.e., the one with the highest probability of success [8]. In order to apply these axioms, parallel functional and physical hierarchies are constructed, the latter containing the physical design solutions. The impact of $\mathrm{AD}$ is that the designer learns how to construct large design hierarchies quickly that are more structured, thus freeing more time for mastering applications [9].

\subsection{Workshop to define Customer Needs (CNs)}

In the workshop, the research team collected the requirements and needs and categorized them in the following groups [10]:

- Constraints (Cs) are usually hard limits or values (minimum, maximum, between).

- Functional Requirements help the designer in the determination of the sub-levels requirements and related design solutions. They should be independent from each other to comply with axiom one, reduce complexity of the system design and are characterizing the functional needs of the artifact.

The following CNs could be identified (see table 1):

Table 1. Customer Needs (CNs).

\begin{tabular}{|c|c|c|}
\hline Nr. & Customer Needs & C, FR, \\
\hline $\mathrm{CN}_{1}$ & $\begin{array}{c}\text { Guarantee the safety of the operator when } \\
\text { is operating in collaboration with the } \\
\text { robot into the workstation }\end{array}$ & $\mathrm{FR}_{1}$ \\
\hline $\mathrm{CN}_{2}$ & $\begin{array}{c}\text { Prevent unexpected dangerous contact } \\
\text { into free-access zone of the workstation }\end{array}$ & $\mathrm{FR}_{2}$ \\
\hline $\mathrm{CN}_{3}$ & $\begin{array}{c}\text { Isolate the hazard zone of the workstation } \\
\mathrm{CN}_{4}\end{array}$ & $\mathrm{FR}_{3}$ \\
\hline $\mathrm{CN}_{5}$ & $\begin{array}{c}\text { Use the existing workstation for further } \\
\text { improvements }\end{array}$ & $\mathrm{C}_{1}$ \\
\hline $\mathrm{CN}_{6}$ & $\begin{array}{c}\text { Re-use the single workstation components } \\
\text { for other applications }\end{array}$ & $\mathrm{C}_{3}$ \\
\hline
\end{tabular}

It is important to underline that, according to the $\mathrm{CNs}$, some FRs will be related to the design of the collaborative (shared) workspace and other to the notcollaborative workspace.

\subsection{Definition of high-level Functional Requirements (FRs) and Design Parameters (DPs)}

The highest level of FRs and DPs are:

$\mathrm{FR}_{0}$ Achieve an acceptable level of safety for mechanical risks that could arise from unintentional HR physical interaction.

$\mathrm{DP}_{0}$ Technical guidelines for a safe collaborative workstation design through the maximum reduction of risks probability and gravity (using, in the first instance, the major standards ISO 12100:2010 [11] and ISO 10218-2:2011 [12]).

Based on the outcome of the initial workshop, the following Cs for the design were defined:

$\mathrm{C}_{1} \quad$ Existing workstation as starting point.

$\mathrm{C}_{2} \quad$ Maximum space of 4 square meters.

$\mathrm{C}_{3} \quad$ Modular system with standard components.

Furthermore, the remaining CNs were associated to high-level FRs and relative DPs:

$\mathrm{FR}_{1} \quad$ Define the intrinsic safety parameters that can be set into the robot control system in order to reduce the intensity of unexpected HR contacts in the collaborative workspace.

$\mathrm{FR}_{2}$ Define the safety functions that depend on a control system in order to prevent unexpected HR contacts.

$\mathrm{FR}_{3} \quad$ Define the safety functions that do not depend on a control system in order to physically block the access to dangerous zone.

$\mathrm{DP}_{1}$ Operator protection during unexpected (but allowed) HR contacts through the energy exchange reduction according to "Power and Force Limiting" approach. Use, in the first instance, the guidelines explained in ISO 10218 1:2011 [13] and ISO TS 15066:2016 section 5.5.5 [2].

$\mathrm{DP}_{2} \quad$ Operator protection through an active prevention of HR contacts. Use, in the first instance, the guidelines explained in ISO 13849-1:2015 [14].

$\mathrm{DP}_{3} \quad$ Operator protection through the avoidance of HR contacts using physical limitations. Use, in the first instance, the guidelines explained in ISO 14120:2015 [15].

In order to clearly identify the link between the different DPs and FRs, the following "Relational Matrix" (see Fig.3) has been developed. The role of that matrix is to identify the different connections between the standards that can be directly addressed to the DPs. The links are obtained from the list of normative references contained in the first introductory part of every mentioned standard. This matrix shows that 
standards for safety used for the design of a collaborative robotic cell are often very coupled, making them hard to implement appropriately.

Table 2. Collaborative robotic cell: main standards for the safety systems design.

\begin{tabular}{|l|c|c|}
\hline \multicolumn{1}{|c|}{ Title } & $\begin{array}{c}\text { Standard } \\
\text { type }\end{array}$ & Code \\
\hline $\begin{array}{l}\text { Robots and robotic devices -- Safety requirements for industrial } \\
\text { robots -- Part 1: Robots }\end{array}$ & C & ISO 10218-1 : 2011 \\
\hline $\begin{array}{l}\text { Safety requirements for industrial robot -- Part 2: Robot } \\
\text { systems and integration }\end{array}$ & C & ISO 10218-2 : 2011 \\
\hline $\begin{array}{l}\text { Safety of machinery -- General principles for design -- Risk } \\
\text { assessment and risk reduction }\end{array}$ & A & ISO 12100 : 2010 \\
\hline $\begin{array}{l}\text { Safety of machinery - Safety-related parts of control systems } \\
- \text { Part 1: General principles for design }\end{array}$ & B & ISO 13849-1: 2015 \\
\hline $\begin{array}{l}\text { Safety of machinery -- Minimum gaps to avoid crushing of parts } \\
\text { of the human body }\end{array}$ & B & ISO 13854: 2017 \\
\hline $\begin{array}{l}\text { Safety of machinery -- Positioning of safeguards with respect to } \\
\text { the approach speeds of parts of the human body }\end{array}$ & B & ISO 13855 : 2010 \\
\hline $\begin{array}{l}\text { Safety of machinery -- Safety distances to prevent hazard zones } \\
\text { being reached by upper and lower limbs }\end{array}$ & B & ISO 13857: 2008 \\
\hline Safety of machinery -- Prevention of unexpected start-up & B & ISO 14118: 2017 \\
\hline $\begin{array}{l}\text { Safety of machinery -- Guards -- General requirements for the } \\
\text { design and construction of fixed and movable guards }\end{array}$ & B & ISO 14120: 2015 \\
\hline $\begin{array}{l}\text { Robots and robotic devices -- Collaborative robots } \\
\text { Safety of machinery - Application of protective equipment to } \\
\text { detect the presence of persons }\end{array}$ & C & ISO TS 15066 : 2016 \\
\hline
\end{tabular}

Table 2 shows the list of main standards used for the design of a collaborative robotic cell.

\begin{tabular}{|c|c|c|c|c|c|c|c|c|c|c|c|}
\hline \multicolumn{12}{|c|}{ Relational Matrix } \\
\hline Code & $\begin{array}{c}\text { ISO } \\
10218-1\end{array}$ & $\begin{array}{c}\text { ISO } \\
10218-2\end{array}$ & $\begin{array}{c}\text { ISO } \\
12100 \\
\end{array}$ & $\begin{array}{c}\text { ISO } \\
13849-1\end{array}$ & $\begin{array}{c}150 \\
13854 \\
\end{array}$ & $\begin{array}{c}\begin{array}{c}150 \\
13855\end{array} \\
\end{array}$ & $\begin{array}{c}150 \\
13857\end{array}$ & $\begin{array}{c}\text { ISO } \\
14118\end{array}$ & $\begin{array}{c}\text { ISO } \\
14120 \\
\end{array}$ & $\begin{array}{l}\text { ISO TS } \\
15066 \\
\end{array}$ & $\begin{array}{c}\text { IEC } \\
62046 \\
\end{array}$ \\
\hline $\begin{array}{c}\text { 150 } \\
10218-1\end{array}$ & & $\mathrm{x}$ & $x$ & $\mathrm{x}$ & & & & & & & \\
\hline $\begin{array}{c}\text { Iso } \\
10218-2\end{array}$ & & & $x$ & $x$ & $x$ & $x$ & $x$ & & $x$ & & $x$ \\
\hline $\begin{array}{c}\text { Iso } \\
12100\end{array}$ & & & & & & & & & & & \\
\hline $\begin{array}{c}150 \\
13849-1\end{array}$ & & & $x$ & & & & & & & & \\
\hline $\begin{array}{c}\text { Iso } \\
13854\end{array}$ & & & $x$ & & & & $x$ & & & & \\
\hline $\begin{array}{c}\text { Iso } \\
13855\end{array}$ & & & $x$ & & & & $x$ & & & & \\
\hline $\begin{array}{c}\text { ISO } \\
13857\end{array}$ & & & $x$ & & & & & & & & \\
\hline $\begin{array}{c}\text { Iso } \\
14118\end{array}$ & & & $x$ & $\mathrm{x}$ & & & & & & & \\
\hline $\begin{array}{c}\text { Iso } \\
14120\end{array}$ & & & $x$ & & & $\mathrm{x}$ & $\mathrm{x}$ & & & & \\
\hline $\begin{array}{l}\text { ISO TS } \\
15066\end{array}$ & $x$ & $x$ & $x$ & & & $x$ & & & & & $\mathrm{x}$ \\
\hline $\begin{array}{c}\text { IEC } \\
62046\end{array}$ & & & $x$ & $\mathrm{x}$ & & $\mathrm{x}$ & & & & & \\
\hline
\end{tabular}

Fig. 3. Relational Matrix about main safety of machinery standards for robotic-cell applications.

The design matrix on the first level is decoupled and shows the dependencies between the solutions (DPs) and the functional requirements (FRs):

$$
\left\{\begin{array}{l}
\mathrm{FR}_{1} \\
\mathrm{FR}_{2} \\
\mathrm{FR}_{3}
\end{array}\right\}=\left[\begin{array}{ccc}
X & X & 0 \\
0 & X & 0 \\
0 & 0 & X
\end{array}\right]\left\{\begin{array}{l}
D P_{1} \\
D P_{2} \\
D P_{3}
\end{array}\right\}
$$

According to the Relational Matrix, ISO 13849-1 is recalled in ISO 10218-1. For this reason, DP2 has also influence on FR1 and FR2. This off-diagonal interaction shows a coupling of DPs and other FRs. Fig. 4 shows the FR-DP tree of the highest hierarchical levels.

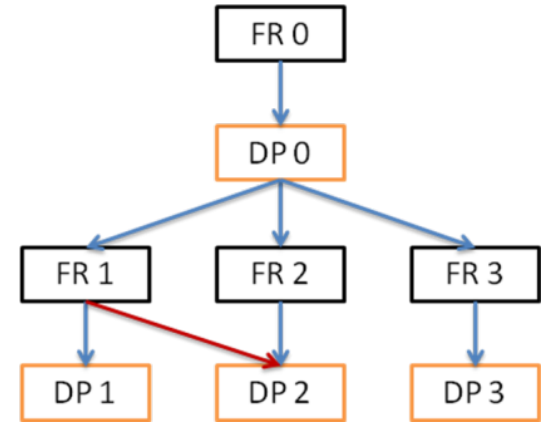

Fig. 4. Design decomposition at highest-level.

\subsection{Decomposition and mapping process}

The decomposition process of top-level FRs and DPs aims to transform the abstract requirements into more tangible parameters that are close to practical design guidelines and therefore relevant for the collaborative workstation implementation. The FR-DP pairs on the highest hierarchical level are the starting point for the top-down decomposition and mapping process. The decomposition is performed separately for each of the FR-DP pairs shown in Fig. 4 to obtain a better understanding of the process.

\subsection{1 $F R_{1}-D P_{1}-$ Reduction of energy exchange during unexpected (but allowed) HR contacts}

The design of the safety systems that safeguard the operator during unexpected (but allowed) HR contacts can be designed by reducing the energy exchange according to "Power and Force Limiting" approach. For the implementation of this DP the guidelines explained in ISO 10218-1:2011 [13] and ISO TS 15066:2016 section 5.5.5 [2] can be applied.

\subsection{2 $F R_{2}-D P_{2}-$ Actively prevention of $H R$ contact}

The design of the safety systems that aims to actively prevent HR unexpected contacts can be satisfied using different complementary approaches. Depending on the final application, it is possible to apply one or more combined solutions.

Starting from FR2., further FRs and DPs of the successive hierarchical level can be defined as follows:

$\mathrm{FR}_{2.1}$ Monitor HR speed and separation.

$\mathrm{FR}_{2.2}$ Achive safety from rated monitored stop devices.

$\mathrm{FR}_{2.3}$ Achive safety from protective equipment to detect presence of persons.

$\mathrm{FR}_{2.4}$ Position the safeguards with respect to the human body part speed.

$\mathrm{FR}_{2.5}$ Prevent an unexpected machine start-up.

$\mathrm{DP}_{2.1}$ Guidelines explained in ISO TS 15066:2016 section 5.5.4 [2]. 
$\mathrm{DP}_{2.2}$ Guidelines explained in ISO TS 15066:2016 section 5.5.2 [2].

$\mathrm{DP}_{2.3}$ Guidelines explained in IEC 62046:2018 [16].

$\mathrm{DP}_{2.4}$ Guidelines explained in ISO 13855:2010 [17].

$\mathrm{DP}_{2.5}$ Guidelines explained in ISO 14118:2017 [18].

The design matrix shows a decoupled design:

$$
\left\{\begin{array}{l}
F R_{2.1} \\
F R_{2.2} \\
F R_{2.3} \\
F R_{2.4} \\
F R_{2.5}
\end{array}\right\}=\left[\begin{array}{ccccc}
X & 0 & X & X & 0 \\
0 & X & 0 & X & 0 \\
0 & 0 & X & X & 0 \\
0 & 0 & 0 & X & 0 \\
0 & 0 & 0 & 0 & X
\end{array}\right]\left\{\begin{array}{l}
D P_{2.1} \\
D P_{2.2} \\
D P_{2.3} \\
D P_{2.4} \\
D P_{2.5}
\end{array}\right\}
$$

According to the Relational Matrix, ISO 13855 and IEC 62046 are recalled in ISO TS 15066 (only for section 5.5.4). Furthermore, ISO 13855 is also recalled in IEC 62046. Finally, ISO TS 15066 is addressed to two DPs $\left(\mathrm{DP}_{2.1}\right.$ with section 5.5.4 and $\mathrm{DP}_{2.2}$ whit section 5.5.2). For these reasons, $\mathrm{DP}_{2.3}$ has influence on $\mathrm{FR}_{2.1}$ and $\mathrm{FR}_{2.3}$ and $\mathrm{DP}_{2.4}$ has influence on $\mathrm{FR}_{2.1}, \mathrm{FR}_{2.2}, \mathrm{FR}_{2.3}$ and $\mathrm{FR}_{2.4}$. Also in this case, the off-diagonal interaction shows a coupling of DPs and other FRs.

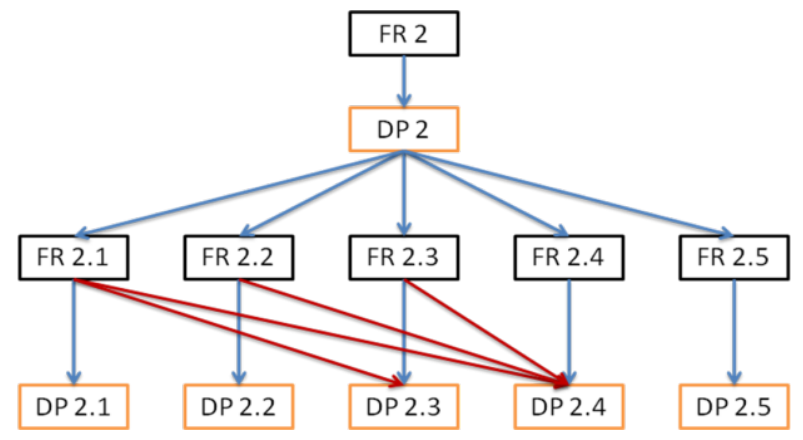

Fig. 5. Design decomposition $\mathrm{FR}_{2 . \mathrm{n}}-\mathrm{DP}_{2 . \mathrm{n}}$.

\subsection{3 $F R_{3}-D P_{3}-$ Avoidance of $H R$ contacts through physical limitations}

The design of the safety systems that aims safeguard the operator by avoiding HR contacts using physical limitations can be satisfied through the preventive design of the components of the robotic cell as well as the design of safeguards.

Starting from FR3, further FRs and DPs of the successive hierarchical level can be defined as follows:

$\mathrm{FR}_{3.1}$ Avoid forcing of parts of the human body.

$\mathrm{FR}_{3.2}$ Prevent hazard zones being reached by operator during manual work activities.

$\mathrm{DP}_{3.1}$ Guidelines explained in ISO 13854:2017 [19].

$\mathrm{DP}_{3.2}$ Guidelines explained in ISO 13857:2008 [20].

The design matrix shows a decoupled design:

$$
\left\{\begin{array}{l}
F R_{3.1} \\
F R_{3.2}
\end{array}\right\}=\left[\begin{array}{ll}
X & X \\
0 & X
\end{array}\right]\left\{\begin{array}{l}
D P_{3.1} \\
D P_{3.2}
\end{array}\right\}
$$

According to the Relational Matrix, ISO 13857 is recalled in ISO 13854. For this reason, DP3.2 has also influence on FR3.1 and FR3.2. This off-diagonal interaction shows a coupling of DPs and other FRs. Fig. 6 shows the FR-DP tree:

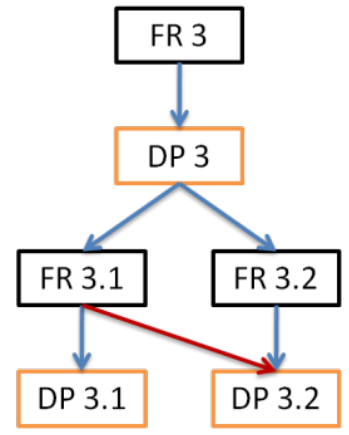

Fig. 6. Design decomposition $\mathrm{FR}_{3 . \mathrm{n}}-\mathrm{DP}_{3 . \mathrm{n}}$.

\subsubsection{Overall relationships}

Following, Fig. 7 shows the overall relationships between FRs and DPs of first, second and third level.

As showed, there is also a link between section 2 and section 3. In particular, FR2.4 and DP3.2 since the Relational Matrix shows a connection between ISO 13855 and ISO 13857.

\subsubsection{Design matrix and summary}

The complexity of the safety systems design for the implementation of the collaborative workstation was reduced trough the Axiomatic Design approach, in particular using the decomposition and mapping process. This approach helps the research team to better structure the safety requirements and to systematically obtain the design solutions (DPs), also respecting the constraints identified in section 4.2. The final design matrix was implemented using "Acclaro DFSS" software and is

\begin{tabular}{|c|c|c|c|c|c|c|c|c|c|c|c|}
\hline & $\underset{0}{0}$ & $\Xi$ & $\underset{N}{\sigma}$ & 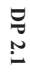 & 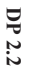 & 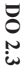 & 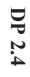 & 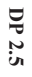 & $\underset{\omega}{\sigma}$ & 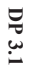 & $\underset{i}{\underset{i}{W}}$ \\
\hline FR 0 & $\mathbf{X}$ & & & & & & & & & & \\
\hline FR 1 & & $\mathbf{X}$ & $\mathbf{X}$ & 0 & 0 & 0 & 0 & 0 & 0 & o & 0 \\
\hline FR 2 & & 0 & $\mathbf{X}$ & & & & & & 0 & 0 & 0 \\
\hline FR 2.1 & & 0 & & $\mathbf{X}$ & 0 & $\mathbf{X}$ & $\mathbf{X}$ & 0 & 0 & 0 & 0 \\
\hline FR 2.2 & & 0 & & 0 & $\mathbf{X}$ & 0 & $\mathbf{X}$ & 0 & 0 & 0 & 0 \\
\hline FR 2.3 & & 0 & & 0 & 0 & $\mathbf{X}$ & $\mathbf{X}$ & 0 & 0 & 0 & 0 \\
\hline FR 2.4 & & 0 & & 0 & 0 & 0 & $\mathbf{X}$ & 0 & 0 & 0 & $\mathbf{X}$ \\
\hline FR 2.5 & & 0 & & 0 & 0 & 0 & 0 & $\mathbf{X}$ & 0 & o & 0 \\
\hline FR 3 & & 0 & 0 & 0 & 0 & 0 & 0 & 0 & $\mathbf{X}$ & & \\
\hline FR 3.1 & & 0 & 0 & 0 & 0 & 0 & 0 & 0 & & X & X \\
\hline FR 3.2 & & 0 & 0 & 0 & 0 & 0 & 0 & 0 & & 0 & $\mathbf{X}$ \\
\hline
\end{tabular}
shown in Fig. 8:

Fig. 8. Summarizing first, second and third level design matrix. 


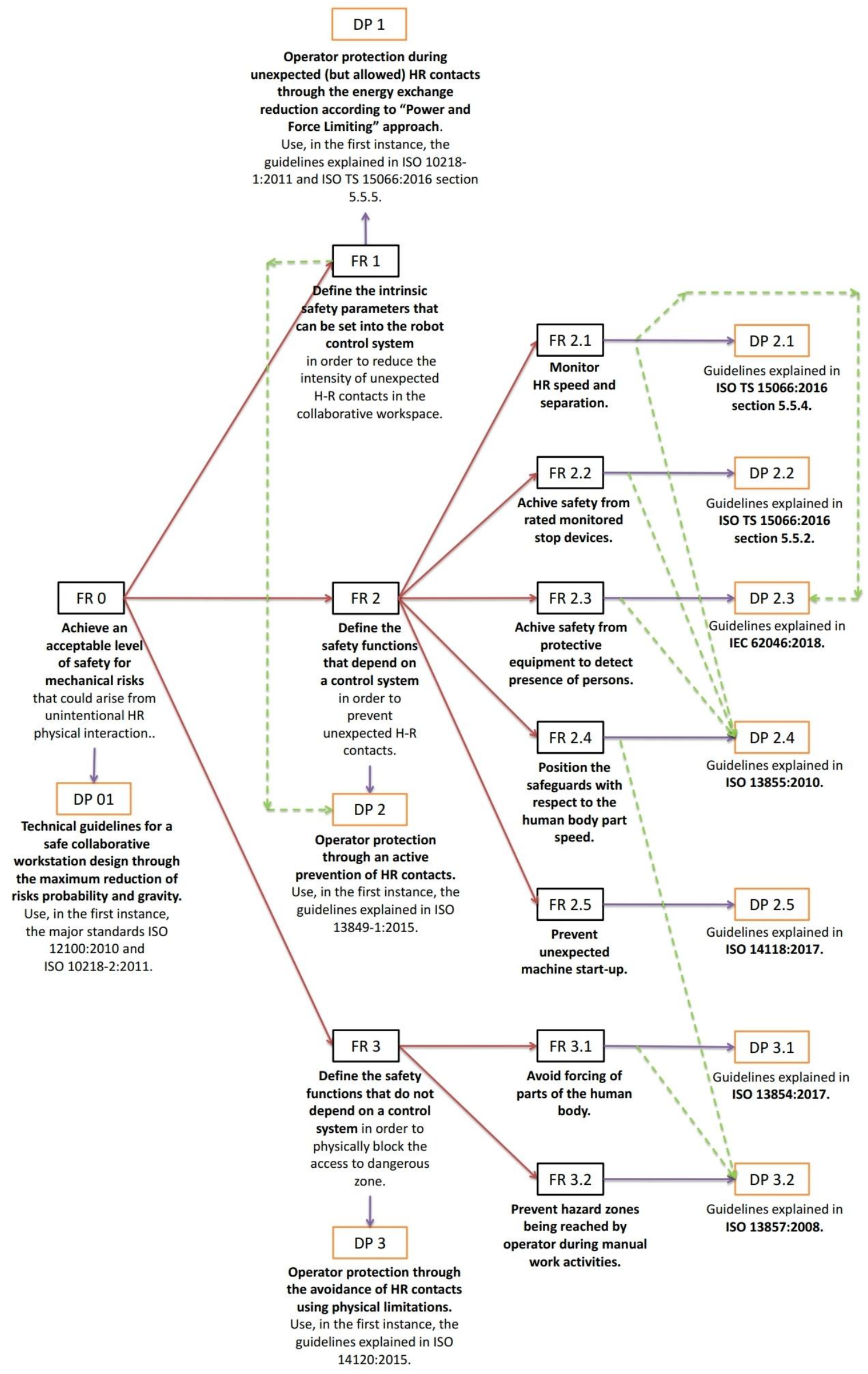

Fig. 7. First, second and third level overall relationships between FRs and DPs. 
The design matrix is triangular and shows a decoupled design, which means that the Independence Axiom can be satisfied if the safety systems design sequence is correct. According to the proposed solution, DP2 has also influence on FR1 because, in general, the safety performance levels indicated in ISO 13849-1:2015 are requirements for the design of the safety-related control system of an industrial robot. In addition, DP2.3 has also influence on FR2.1 since the design of "Speed and Separation Monitoring Systems" needs the monitoring of the operators speed as indicated in IEC 62046:2018. DP2.4 has influence on FR2.1, FR2.2 and FR2.3 since the design of "Speed and Separation Systems", "Safety Rated Monitored Stop" and electrosensitive safety devices requires the indications discussed in ISO 13855:2010 in terms of position of safeguards in relationships to human motion.

In addition, DP3.2 has also influence on FR3.1 because the design of the parts of the workstation which has to avoid the forcing of human body parts is linked to ISO 13857:2008 which is related to the prevention of the achievement of hazard zones during manual work activities. Finally, DP3.2 has also influence on FR2.4 since the design of safety systems related to the operators speed requires the indications contained in ISO 13857:2008.

\section{Concept of the Collaborative Human- Robot Assembly Workplace based on the results from the AD approach}

Fig. 9 explains a preliminary concept layout of the new collaborative workstation, including the main safety systems and their related standards. As shown, there will be a collaborative space, where human and robot will share the workspace in order to perform a common production task, and a not-collaborative space, where operators are not allowed and the robot can work more performing.

Of course, different limited spaces involves different safety requirements and systems, which are regulated by different standards.

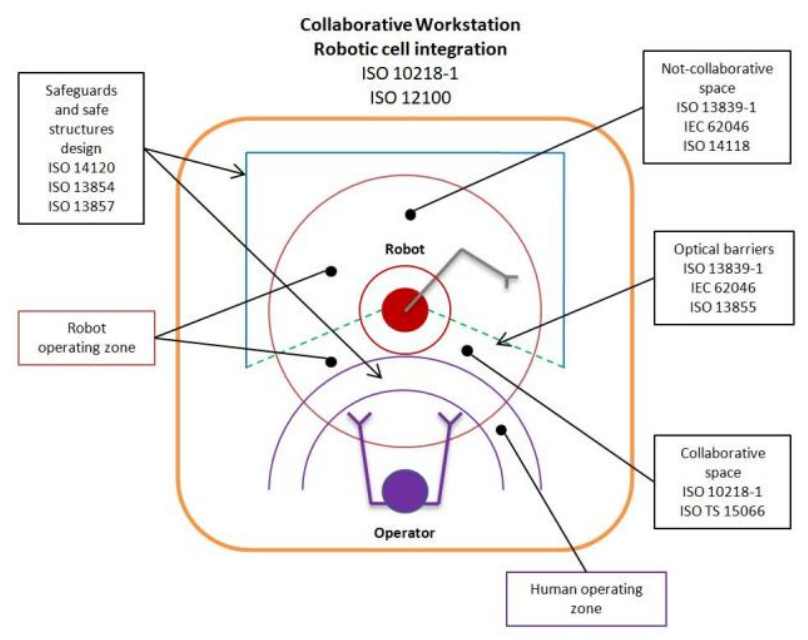

Fig. 9. New design of the collaborative assembly workplace.

\section{Conclusion and outlook for further research}

The present research work has shown the potential applicability of Axiomatic Design to the study and development of a complex situation such as the design of safety systems for a collaborative HR workstation, also considering OHS requirements. The output of that design is a list of standard-related guidelines, which can helps technicians and designer in implementing safety systems for industrial collaborative robot applications. These guidelines can simplify the complexity of the safety systems design stage, which can be very substantial due to the presence of a person into a robotic cell.

Future improvements can be:

- The further development of the proposed guidelines in order to define more precise safety parameters using an Axiomatic Design approach;

- The application of an Axiomatic Design approach to the design of the ergonomics solutions for HR collaborative workstations related to main international OHS standards;

- The introduction of production efficiency considerations as Non-Functional Requirements (non-FRs), in combination to safety and ergonomics requirements (FRs).

This research was conducted in the research project "SME 4.0". As the working title already reveals, research focuses on the development of new concepts of Industry 4.0 that are especially suitable for SME.

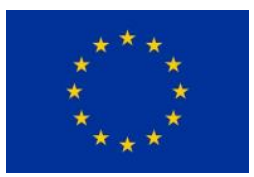

This project has received funding from the European Union's Horizon 2020 research and innovation program under the Marie Skłodowska-Curie grant agreement No 734713.

\section{References}

1. M. Huber, M. Rickert, A. Knoll, T. Brandt, S. Glasauer, Human-robot interaction in handingover tasks, , the 17th International Symposium on Robot and Human Interactive Communication, 1-3 August 2008, Munich, Germany, 107-112, IEEE, (2008).

2. ISO, Ts 15066: 2011, Robots and robotic devices - collaborative robots, Geneva, Switzerland: International Organization for Standardization, (2011).

3. B. Matthias, T. Reisinger, Example application of ISO/TS 15066 to a collaborative assembly scenario, the 47th International Symposium on Robotics (ISR), 21-22 June 2016, Munich, Germany, 1-5, VDE (2016).

4. P. Fantini, M. Pinzone, M. Taisch, Placing the operator at the centre of Industry 4.0 design: Modelling and assessing human activities within cyber-physical systems, Computers \& Industrial Engineering, (2018, in press). 
5. B.C. Pirvu, C.B. Zamfirescu, D. Gorecky, Engineering insights from an anthropocentric cyber-physical system: A case study for an assembly station. Mechatronics, 34, 147-159, (2016).

6. J. Fryman, B. Matthias, Safety of industrial robots: From conventional to collaborative applications, 7th German Conference on Robotics, 21-22 May 2012, Munich, Germany, 1-5, VDE, (2012).

7. D.T. Matt, E. Rauch, P. Dallasega, Minifactory - a learning factory concept for students and small and medium sized enterprises, Procedia CIRP, 17, 178-183 (2014).

8. N.P. Suh, Axiomatic Design - Advances and Applications. New York, Oxford University Press, (2009).

9. C.A. Brown, Teaching axiomatic design to engineers - Theory, applications, and software, Journal of Manufacturing Systems, 24, 3, 186195, (2005).

10. M.K. Thompson, A Classification of Procedural Errors in the Definition of Functional Requirements, in Axiomatic Design Theory, Proceedings of the 7thInternational Conference on Axiomatic Design, Worcester, MA, 107-112, (2013).

11. ISO, 12100: 2010, Safety of machineryGeneral principles for design-Risk assessment and risk reduction, Geneva, Switzerland: International Organization for Standardization, (2010).

12. ISO, 10218-1: 2011, Robots and robotic devices-Safety requirements for industrial robots-Part 1: Robots, Geneva, Switzerland: International Organization for Standardization, (2011).

13. ISO, 10218-2: 2011, Robots and robotic devices-Safety requirements for industrial robots-Part 2: Robot systems and integration, Geneva, Switzerland: International Organization for Standardization, (2011).

14. ISO, 13849-1 : 2015, Safety of machinerySafety-related parts of control systems, Part 1: General principles for design, Geneva, Switzerland: International Organization for Standardization, (2015).

15. ISO, 14120: 2015, Safety of machineryGuards-General requirements for the design and construction of fixed and movable guards, Geneva, Switzerland: International Organization for Standardization, (2015).
16. IEC 62046:2018, Safety of machineryApplication of protective equipment to detect the presence of persons, Geneva, Switzerland: International Electrotechnical Commission, (2018).

17. ISO, 13855: 2010, Safety of machineryPositioning of safeguards with respect to the approach speeds of parts of the human body, Geneva, Switzerland: International Organization for Standardization, (2010).

18. ISO, 14118:2015, Safety of machineryPrevention of unexpected start-up, Geneva, Switzerland: International Organization for Standardization, (2015).

19. ISO, 13854:2017, Safety of machineryMinimum gaps to avoid crushing of parts of the human body, Geneva, Switzerland: International Organization for Standardization, (2017).

20. ISO, 13857:2017, Safety of machinerySafety distances to prevent hazard zones being reached by upper and lower limbs, Geneva, Switzerland: International Organization for Standardization, (2017). 